\title{
Evaluation of Potential Effect of Menthol Solution on Oral Hygiene Status of Dental Students in a University in Iraq
}

\author{
Nidhal A Ali ${ }^{1}$, Maha J Abbas ${ }^{1}$ and Fouad H AL-Bayaty ${ }^{2 *}$ \\ ${ }^{1}$ Faculty of Dentistry, Al Mustansiriya University, Baghdad, Iraq, ${ }^{2}$ Centre of the studies for Periodontology, Faculty of Dentistry, \\ Universiti Teknologi MARA, Shah Alam, Malaysia
}

*For correspondence: Email: drfouadhm@yahoo.com; Tel: 006 03-5543 5818; Fax: 00603-5543 5803

\begin{abstract}
Purpose: To test the effect of menthol extract on the oral hygiene status of dental students of Faculty of Dentistry, Al- Mustansiriya University, Baghdad, Iraq.

Methods: A solution (18 $\mathrm{mg} \%$ ) of menthol was prepared by dissolving menthol crystals in absolute ethanol. Chlorhexidine (CHX, $0.2 \%$ ) and deionized water were used as positive and negative controls, respectively. Menthol was examined for its toxic effect. Twenty male albino mice were injected intraperitoneally with a low $(10 \mathrm{mg} / \mathrm{ml})$ and high dose $(50 \mathrm{mg} / \mathrm{ml})$ of the menthol solution, and acute toxicity $\left(L D_{50}\right)$ calculated. A double-blind crossover was designed to test plaque re-growth over 5 days. Thirty male dental student volunteers were asked to cease tooth cleaning and then rinse with $10 \mathrm{ml}$ of menthol solution three times daily for $1.5 \mathrm{~min}$, twice daily with $\mathrm{CHX}$ and deionized water. Plaque, gingival and bleeding scores were recorded on days 0 and 5 . A washout period of 2 weeks was allowed, and then a new test was initiated. The data obtained were analysed statistically.

Results: Menthol mouthwash demonstrates a significant reduction in plaque, gingival and bleeding indices of $0.56,0.45$ and 0.03 , respectively. $\mathrm{CHX}$ induced a greater reduction in these parameters than menthol with indices of $0.14,0.26$, and 0.04 , respectively.

Conclusion: Menthol mouth rinse $(0.018 \%)$ is an antiplaque and anti-gingivitis agent, though less effective than $\mathrm{CHX}$.
\end{abstract}

Keywords: Menthol mouth rinse, Chlorhexidine, Dental plaque, Gingivitis, Oral hygiene

\begin{abstract}
Tropical Journal of Pharmaceutical Research is indexed by Science Citation Index (SciSearch), Scopus, International Pharmaceutical Abstract, Chemical Abstracts, Embase, Index Copernicus, EBSCO, African Index Medicus, JournalSeek, Journal Citation Reports/Science Edition, Directory of Open Access Journals (DOAJ), African Journal Online, Bioline International, Open-J-Gate and Pharmacy Abstracts
\end{abstract}

\section{INTRODUCTION}

A number of clinical studies have shown the effects of using mouth washes extracted from herbs such as Selvadora persica [1], Sanguinarina [2] Quercus infectoria [3] Capparis spinosa [4] and cinnamon in the prevention of dental plaque accumulation and subsequent gingival inflammation.

Chlorhexidine is one of most effective antiseptics for dental plaque inhibition and the prevention of gingivitis when used twice daily as a mouth rinse
[5,6]. Oral use of chlorhexidine as a mouth rinse has been reported to have a number of side effects including: brown discoloration of the teeth, some restorative materials and mucosa; a bitter taste; and sometimes sloughing of oral mucosa, all of which have restricted its general use [7]. In order to overcome such side effects, the World Health Organization (WHO) has urged researchers to investigate the possible use of natural products such as herb and plant extracts. Menthol is a covalent organic compound obtained from peppermint or other mint oil or made synthetically through a chemical process [8]. It is commonly used in oral hygiene products 
and bad breath remedies such as mouth washes, toothpaste, tongue spray, and more generally as a food flavouring agent (as in chewing gum and candy). Its antimicrobial activity has been demonstrated against several strains of Grampositive and Gram-negative bacteria [9].

The objective of the study was to test the effects of menthol crystal aqueous extracts on oral hygiene status among a group of dental student volunteers from the Faculty of Dentistry, AlMustansiriya University, Baghdad, Iraq.

\section{EXPERIMENTAL}

Menthol crystals (molecular formula C10 H20O) were purchased from Sigma Aldrich USA.

\section{Evaluation of toxicological profile of the extract}

The study was approved by the Research Committee on the Ethical Use of Animals at the Research Faculty of Science at Baghdad University (no. 25/12/2010/310/17). All animals received care according to the criteria outlined in the "Guide for the Care and Use of Laboratory Animals" prepared by the National Academy of Sciences and published by the National Institutes of Health. Acute toxicity test was carried out in the Faculty of Science at Baghdad University. Twenty male albino mice were injected intraperitoneally with a low $(10 \mathrm{mg} / \mathrm{ml}$ body weight) and a high dose (50 $\mathrm{mg} / \mathrm{ml}$ body weight) of aqueous-ethanol menthol solution (18 $\mathrm{mg} \%$ ). Acute toxicity (LD50) was calculated as the geometrical mean of the dose that resulted in $100 \%$ lethality and that which caused no lethality at all.

\section{Preparation of mouthwash}

Menthol crystal aqueous extract (18 $\mathrm{mg} \%$ ) was prepared by dissolving $18 \mathrm{mg}$ menthol crystals in $0.1 \mathrm{ml}$ absolute ethanol and, making up the volume to $100 \mathrm{ml}$ of sterile deionized water. Chlorhexidine digluconate mouthwash $(0.2 \%)$ was used as a positive control. Sterilized distilled water was used as a negative control. The mouthwashes were kept in identical but coded bottles. Instructions for use were clearly written on them.

\section{Study design}

The study was approved by the Human Research and Ethical Committee at the Faculty of Dentistry, Al- Mustansiriya University (Ethic no. $1 / 2 / 2011 / 69 / 411)$. This study was performed according to the international, national, and institutional rules on human care and techniques [10]. The study was a double blind, in which a group of 30 male dental student volunteers (aged 22 - 23 years of age) participated at the Faculty of Dentistry, Al-Mustansiriya University, Baghdad, Iraq. All the subjects had only gingivitis (pocket depth $\leq 3 \mathrm{~mm}$, no attachment loss) and were without any fixed or removable oral appliances. Individuals who had a history of any relevant systemic disease or drug usage were excluded. Eligible subjects were informed of the purpose of this study and the products being evaluated. Before participating in the study, each of them provided a signed (witnessed) consent to participate in this study.

Plaque, gingival bleeding and gingival indices were recorded on day zero before using the mouth rinses in order to provide baseline data. The volunteers participated in three test periods. Each period lasted five days from Sunday to Thursday. Every day, the volunteers were instructed to rinse with each either of the following mouth rinses and they were instructed to stop any mechanical plaque control:

1. Test solution: Menthol extract at $18 \mathrm{mg} \%$ concentration. The instruction was to rinse three times daily (according to sub-sensitivity test) with $10 \mathrm{ml}$ of the solution for a duration of $1.5 \mathrm{~min}$.

2. Positive control: Chlorhexidine digluconate solution $(0.2 \%$, Thornton \& Ross Ltd, Linthwaite, Huddersfield, West Yorkshire, HD7 5QH) $10 \mathrm{ml}$ two times daily, each time for a duration of 1.5 $\min$.

3. Negative control: Sterilized distilled water 10 $\mathrm{ml}, 3$ times daily for a duration of $1.5 \mathrm{~min}$.

They were also instructed not to change their eating and drinking habits. At the end of each test period, a washout period of two weeks was allowed during which the volunteers were instructed to resume their previous mechanical plaque control measures [2]. Examination procedures were performed on a dental chair in the Department of Preventive, Pedodontic Dentistry at the Faculty of Dentistry at AlMustansiriya University with the aid of a dental mouth mirror and a Williams periodontal probe. A single clinician carried out all examinations. Plaque [11], gingival bleeding [12] and gingival indices [11] were recorded on day five.

Measurement of plaque index (PLI) and gingival index (GI)

Plaque index was used to assess the extent of soft deposits, and to measure the difference in 
the thickness of debris at the gingival margin. This was used in conjunction with a gingival index, which is a useful method in longitudinal studies and clinical trials. Four gingival scoring units (namely the mesial, distal, buccal and lingual surfaces) were examined by using a mouth mirror, dental explorer and a triple syringe for drying. PLI for area is obtained by totalling 4 unit scores per tooth. PLI score per person is obtained by adding PLI scores per tooth and then dividing this by the number of teeth examined. A score may also be obtained for a segment or group of teeth. The same procedures were also used to calculate $\mathrm{GI}$. Measurement of gingival bleeding point index
(GBI)

Use of a periodontal probe is an easy and suitable way for the practitioner to assess the presence or absence of gingival bleeding. The appearance of bleeding within $10 \mathrm{~s}$ indicates a positive score, which is expressed as a percentage of the total number of gingival margins.

The participants' compliance was evaluated by measuring the remaining volume of the mouthwash that they brought back during their recalls. They were also asked to report any adverse reactions experienced during the use of mouthwashes.

\section{Statistical analysis}

Data were analysed using the SPSS 20 and presented in simple measures of frequencies and percentages for study groups, and the values expressed as: mean, mean difference, standard deviation, standard error. The significance of difference in means was tested using paired sample t-test, the student t-test for two independent means, and ANOVA test. Figures were also used to express the data; a scatter diagram was used to express the correlation between the different parameters. $P \leq 0.05$ was considered to be significant.

\section{RESULTS}

\section{Acute toxicity}

The procedure for the acute toxicity test did not reveal any mortality among the experimental animals, which in turn indicates that this substance is well tolerated.
Elimination of menthol extract from oral cavity

The volunteers in the study group had mean age of $22.5 \pm 0.7$ years. Menthol concentration in saliva provided by the volunteers at various stages of the experiment is shown in Table 1. Results from electronic spectrophotometric testing revealed traces of menthol extract in saliva after $6 \mathrm{~h}$.

Table 1: Concentration of menthol in saliva after mouth wash

\begin{tabular}{lc}
\hline Time & $\begin{array}{c}\text { Saliva of concentration } \\
\text { of menthol (mg \%) }\end{array}$ \\
\hline After 5 min & 8.4 \\
After $1 \mathrm{~h}$ & 6.3 \\
After $2 \mathrm{~h}$ & 5.2 \\
After $3 \mathrm{~h}$ & 4.3 \\
After $4 \mathrm{~h}$ & 2.6 \\
After $5 \mathrm{~h}$ & 1.6 \\
After $6 \mathrm{~h}$ & 0.7 \\
After $8 \mathrm{~h}$ & 0 \\
\hline The distribution of the study group according to their \\
age and gender
\end{tabular}

\section{Effect of mouthwashes on clinical parameters}

After 5 days of daily rinsing, chlorhexidine and menthol mouthwashes led to a significant reduction in the plaque index, gingival index and bleeding point index. This was evidenced by a statistically significant lower mean score ( $p<$ 0.01 ) in the aforementioned parameters. An insignificant difference was found with the negative control (de-ionized water).

Tables 2 and 3 show the mean difference in the mean pre and post plague, gingival and bleeding time indices of methanol and chlorhexidine respectively. Methanol and chlorhexidine had a significantly lower post exposure indices for all the parameters, $p<0.05$ respectively. Chlorhexidine induced a greater difference than menthol (by $0.14,0.26$, and 0.04 on the plaque, gingival and bleeding point $(p<0.03)$ (Table 4$)$. The chlorhexidine agent also induced a more significant difference on the plaque gingival and bleeding point indices than menthol or deionized water $(p<0.05)$ (Table 5$)$.

\section{DISCUSSION}

The acute toxicity test is still of considerable importance for the assessment of the risk posed by new chemical substances and for better control of natural and synthetic agents in the human environment [13]. Our results showed 
Table 2: Mean (pre- and post-) and mean difference of plaque, gingival and bleeding point index following menthol rinse

\begin{tabular}{|c|c|c|c|c|c|c|c|c|}
\hline Index & & Mean & $\begin{array}{l}\text { Mean of } \\
\text { difference }\end{array}$ & $\mathbf{N}$ & SD & SE & $\begin{array}{l}\text { Paired- } \\
\text { sample t- } \\
\text { test }\end{array}$ & $P$-value \\
\hline Plaque index & $\begin{array}{l}\text { Pre- } \\
\text { Post- }\end{array}$ & $\begin{array}{l}1.91 \\
1.35\end{array}$ & 0.56 & $\begin{array}{l}30 \\
30\end{array}$ & $\begin{array}{l}0.32 \\
0.13\end{array}$ & $\begin{array}{l}0.05 \\
0.02\end{array}$ & $\begin{array}{l}12.271 \\
d f=29\end{array}$ & 0.01 \\
\hline Gingival index & $\begin{array}{l}\text { Pre- } \\
\text { Post- }\end{array}$ & $\begin{array}{l}1.90 \\
1.45\end{array}$ & 0.45 & $\begin{array}{l}30 \\
30\end{array}$ & $\begin{array}{l}0.28 \\
0.13\end{array}$ & $\begin{array}{l}0.05 \\
0.02\end{array}$ & $\begin{array}{l}13.047 \\
d f=29\end{array}$ & 0.01 \\
\hline $\begin{array}{l}\text { Bleeding point } \\
\text { index }\end{array}$ & $\begin{array}{l}\text { Pre- } \\
\text { Post- }\end{array}$ & $\begin{array}{l}0.21 \\
0.18\end{array}$ & 0.03 & $\begin{array}{l}30 \\
30\end{array}$ & $\begin{array}{l}0.01 \\
0.01\end{array}$ & $\begin{array}{l}0.001 \\
0.003\end{array}$ & $\begin{array}{l}10.770 \\
d f=29\end{array}$ & 0.01 \\
\hline
\end{tabular}

Table 3: Mean (pre- and post-) and mean difference of plaque, gingival and bleeding point index by using of chlorhexidine agent

\begin{tabular}{|c|c|c|c|c|c|c|c|c|}
\hline Chlorhexidine & ent & Mean & $\begin{array}{l}\text { Mean of } \\
\text { difference }\end{array}$ & $\mathbf{N}$ & SD & SEM & $\begin{array}{l}\text { Paired } \\
\text { sample-t } \\
\text { test }\end{array}$ & $P$-value \\
\hline Plaque index & $\begin{array}{l}\text { Pre } \\
\text { Post }\end{array}$ & $\begin{array}{l}1.69 \\
0.99\end{array}$ & 0.70 & $\begin{array}{l}30 \\
30\end{array}$ & $\begin{array}{l}0.30 \\
0.26\end{array}$ & $\begin{array}{l}0.05 \\
0.04\end{array}$ & $\begin{array}{l}12.271 \\
d f=29\end{array}$ & 0.01 \\
\hline Gingival index & $\begin{array}{l}\text { Pre } \\
\text { Post }\end{array}$ & $\begin{array}{l}1.82 \\
1.11\end{array}$ & 0.71 & $\begin{array}{l}30 \\
30\end{array}$ & $\begin{array}{l}0.29 \\
0.16\end{array}$ & $\begin{array}{l}0.05 \\
0.02\end{array}$ & $\begin{array}{l}13.047 \\
d f=29\end{array}$ & 0.01 \\
\hline $\begin{array}{l}\text { Bleeding point } \\
\text { index }\end{array}$ & $\begin{array}{l}\text { Pre } \\
\text { Post }\end{array}$ & $\begin{array}{l}0.19 \\
0.13\end{array}$ & 0.06 & $\begin{array}{l}30 \\
30 \\
\end{array}$ & $\begin{array}{l}0.007 \\
0.009 \\
\end{array}$ & $\begin{array}{l}0.001 \\
0.001\end{array}$ & $\begin{array}{l}10.770 \\
d f=29\end{array}$ & 0.01 \\
\hline
\end{tabular}

Table 4: Mean difference induced by each agent (pre and post use) and between two agents for plaque, gingival and bleeding point index

\begin{tabular}{|c|c|c|c|c|c|c|c|c|c|}
\hline Parameter & Mouthwash & $\mathbf{N}$ & $\begin{array}{r}\text { Mea } \\
\text { an }\end{array}$ & $\begin{array}{l}\text { difference(pre } \\
\text { ost using of } \\
\text { agent) }\end{array}$ & $\begin{array}{c}\text { Mean } \\
\text { difference } \\
\text { between two } \\
\text { agents } \\
\end{array}$ & SD & SEM & $\begin{array}{l}\text { Independent t- } \\
\text { test }\end{array}$ & $p$-value \\
\hline \multirow[t]{2}{*}{ Plaque index } & Menthol & 30 & & 0.56 & 0.14 & 0.24 & 0.04 & $3.179-$ & 0.02 \\
\hline & Chlorhexidine & 30 & & 0.70 & & 0.23 & 0.04 & $d f=58$ & \\
\hline \multirow[t]{2}{*}{ Gingival index } & x Menthol & 30 & & 0.45 & 0.26 & 0.18 & 0.03 & 5.844- & 0.01 \\
\hline & Chlorhexidine & 30 & & 0.71 & & 0.15 & 0.02 & $d f=58$ & \\
\hline \multirow{2}{*}{$\begin{array}{l}\text { Bleeding poir } \\
\text { index }\end{array}$} & tMenthol & 30 & 0.03 & & 0.04 & 0.01 & 0.002 & -9.868 & 0.01 \\
\hline & Chlorhexidine & 30 & 0.07 & & & 0.01 & 0.002 & $d f=58$ & \\
\hline
\end{tabular}

Table 5: Mean differences (pre- and post- mouth rinse) for plaque, gingival and bleeding point index

\begin{tabular}{|c|c|c|c|c|c|c|c|c|c|}
\hline Parameter & & $\mathbf{N}$ & $\begin{array}{c}\text { Mean } \\
\text { difference }\end{array}$ & SD & SEM & \multicolumn{2}{|c|}{$\begin{array}{l}95 \% \text { Confidence } \\
\text { interval for Mean }\end{array}$} & F-test & $P$-value \\
\hline \multirow{3}{*}{ Plaque index } & Menthol & 30 & 0.56 & 0.24 & 0.04 & 0.46 & 0.65 & 109.522 & $\mathrm{HS}$ \\
\hline & Chlorhexidine & 30 & 0.70 & 0.23 & 0.04 & 0.67 & 0.84 & & \\
\hline & $\begin{array}{l}\text { Deionized } \\
\text { water }\end{array}$ & 30 & 0.01 & 0.04 & 0.007 & 0.004 & 0.03 & & \\
\hline \multirow[t]{3}{*}{ Gingival index } & Menthol & 30 & 0.45 & 0.18 & 0.03 & 0.37 & 0.52 & 157.045 & HS \\
\hline & Chlorhexidine & 30 & 0.71 & 0.15 & 0.02 & 0.65 & 0.76 & & \\
\hline & $\begin{array}{l}\text { Deionized } \\
\text { water }\end{array}$ & 30 & 0.02 & 0.06 & 0.01 & 0.02 & 0.07 & & \\
\hline \multirow{3}{*}{$\begin{array}{l}\text { Bleeding point } \\
\text { index }\end{array}$} & Menthol & 30 & 0.03 & 0.01 & 0.002 & 0.02 & 0.03 & 133.062 & HS \\
\hline & Chlorhexidine & 30 & 0.06 & 0.01 & 0.002 & 0.06 & 0.07 & & \\
\hline & $\begin{array}{l}\text { Deionized } \\
\text { water }\end{array}$ & 30 & 0.001 & 0.01 & 0.003 & 0.003 & 0.01 & & \\
\hline
\end{tabular}


that alcoholic menthol extract is safe and well tolerated.

There is a continued interest in identifying efficient anti plaque agents that could be used daily without side effects $[14,15]$. Folk medicine is a potential source of medicaments and has recently become a focus for dental research $[3,16]$.

All participants satisfactorily completed the study and their returned mouthwashes indicated a good compliance without any significant difference between the residual volume of menthol, $\mathrm{CHX}$ mouth washes or control rinse. Further, there was no report of any adverse effects by mouth washing with the test or control solutions.

Menthol mouth rinse showed immediate release in salivary flow rates which continued to increase after $30 \mathrm{~min}$, then began to reduce slowly. This might be due to the strong mint aroma and taste which led to an increased salivary flow rate [17]. Saliva analysis revealed traces of menthol extract after $6 \mathrm{~h}$ which could justify the use of this extract three times per day.

The trial demonstrated that the use of the menthol extract as a mouthwash resulted in a significant reduction of gingival, plaque and gingival bleeding indices at the end of the mouth rinsing phase. Menthol extract and $\mathrm{CHX}$ mouthwash had a similar anti-gingivitis and antiplaque efficacy.

High means of plaque, bleeding and gingival scores were recorded on baseline examination and decreased notably after the period of rinsing with menthol extract. In addition, by reference to these clinical parameters reduction caused by use of menthol extract mouthwash was significantly greater than the use of the control rinse $(p \leq 0.001)$.

Menthol extract resulted in a significant reduction in the gingival index scores compared to use of the control rinse. These findings would confirm the results of previous studies which have identified the ability of herbal extracts to reduce gingival inflammation parameters $[18,19]$.

In the present study, menthol extract managed to reduce the mean plaque scores from 1.91 to 1.35 after rinsing for a period of five days. This was significantly higher than the control rinse. This is attributed to the antibacterial properties of menthol. Some in vitro studies have failed to reach the same results and have suggested that the in vivo efficacy of herb-based mouth rinses in reducing plaque accumulation must be explained by other mechanisms. Again, the components of the mouth rinse seem to be a crucial factor. Those studies which have tested other plant extracts were unable to demonstrate any benefit in terms of plaque growth and gingival health [20]. Although $\mathrm{CHX}$ has a proven role in reducing plaque accumulation, tooth staining is the major limiting factor for its use in daily practice [21]. This has led to continuous and extensive investigations, seeking alternative agents.

$\mathrm{CHX}$ is considered to be the gold standard because of its superior antiplaque effects, which is a result of its superior degree of persistence on the tooth surface [7]. Results demonstrated that menthol at $18 \mathrm{mg} / \mathrm{ml}$ was equally effective. $\mathrm{CHX}$ rinsing can cause a number of local side effects, such as extrinsic tooth and tongue staining, taste disturbance, and enhanced supragingival calculus formation. $\mathrm{CHX}$ rinsing can also cause desquamation of the oral mucosa [22], but this is less common. On the other hand, menthol does not cause any side effects. Therefore, menthol mouth rinse can be safely considered for longterm use. This being a short-term study, the results can be used as a baseline data for future studies with a similar study design.

\section{CONCLUSION}

Within the limits of the study, it can be concluded that as an antiplaque and anti-gingivitis agent, menthol mouthwash $(0.0018)$ is effective though less effective than chlorhexidine. It is also well tolerated and safe.

\section{REFERENCES}

1. Al-Bayaty $F H$, Al-Koubaisi AH, Ali NAW, Abdulla MA. Effect of mouth wash extracted from Salvadora persica (Miswak) on dental plaque formation: $A$ clinical trail. JMPR, 2010. 4(14): 1446-1454.

2. Abbas DK, Thrane $P$, Othman SJ. Effectiveness of Veadent as a plaque-inhibiting mouthwash. Eur J Oral Sci, 1985. 93(6): 494-497.

3. Walid $H$, Fouad $H$. The effect of Myrtus Communis extract mouth wash on newly dental plaque. J. Coll Dent, 2001. 8: 41-49.

4. Fouad H, Mahmouad WH. The efficacy of Capparis Spinosa herbal extract as an antiplaque agent. J. College. Dentistry, 2001. 10: 85-95.

5. Al-Bayaty F, Taiyeb-Ali H, Abdulla TB, Mahmud MA. Antibacterial effects of Oradex, Gengigel and Salviathymol-n mouthwash on dental biofilm bacteria. AJMR, 2011. 5: 636-42.

6. Ribeiro $L G M$, Hashizume $L N$, Maltz $M$. The effect of different formulations of chlorhexidine in reducing levels of mutans streptococci in the oral cavity: $A$ 
systematic review of the literature. J Dent, 2007. 35(5): 359-370.

7. Addy M Chlorhexidine compared with other locally delivered antimicrobials. J Clin Periodontol 1986. 13(10): 957-964.

8. Al-Bazaz FA, Mohammed A. Effects of Menthol crystals aqueous extracts on salivary Streptococci and Mutans Streptococci in comparison to Chlorhexidine Gluconate (In vivo study). J. Coll. Dent.: 119.9.

9. Abdul Wahid N AL Hashemy $E$ and Abbas M. Effect of Menthol Crystals Aqueous Extracts on the Growth of Candida Albicans Isolated from Saliva of Type II Diabetes Mellitus Patients. JAMR, 2013. 2(4).

10. Human Experimentation: Code of Ethics of the World Medical Association. Br Med J. 1964; 2: 177

11. Silness J, Löe H. Periodontal disease in pregnancy II. Correlation between oral hygiene and periodontal condition. Acta Odontol Scand, 1964. 22(1): 121-135.

12. Bulkacz J, Schuster GS, Singh B, Scott DF. Phospholipase $A$ activity of extracellular products from Bacteroides melaninogenicus on epithelium tissue cultures. J Periodontal Res, 1985. 20(2): 146153.

13. Zbinden G, Roversi MF. Significance of the LD50-test for the toxicological evaluation of chemical substances. Archives of Toxicology, 1981. 47(2): 77-99.

14. Al-Bayaty $F$ Taiyeb-Ali $T$ Abdulla MA Hashim $F$ Antibacterial effect of chlorine dioxide and hyaluronate on dental biofilm. AJMR, 2010. 4(14): 1525-1531.
15. Prabuseenivasan S, Jayakumar M, Ignacimuthu S. In vitro antibacterial activity of some plant essential oils. BMC Complement Altern Med, 2006. 6(1): 39.

16. Al-Bayaty FH Abdulla MA Hassan MIA Ali HM. Effect of Andrographis paniculata leaf extract on wound healing in rats. Nat Prod Res 2012. 26(5): 423-429.

17. Sell CS A fragrant introduction to terpenoid chemistry. 2003: RSC.

18. Shetty PR, Setty SB, Kamat SS, Aldarti AS, Shetty SN. Comparison of the antigingivitis and antiplaque efficacy of the herboral (herbal extract) mouthwash with chlorhexidine and listerine mouthwashes: a clinical study. Pakistan Oral Dental Journal, 2013. 33 No. 1 (April 2013)

19. Pistorius A, Willershausen B, Steinmeier EM, Kreisler M. Efficacy of subgingival irrigation using herbal extracts on gingival inflammation. J Periodontol, 2003. 74(5): 616-622.

20. Pourabbas R, Delazar A. The effect of German chamomile mouthwash on dental plaque and gingival inflammation. IJPR, 2010: 105-109.

21. Aneja KR $R$ Joshi and C Sharma. The antimicrobial potential of ten often used mouthwashes against four dental caries pathogens. jjmicrobiol, 2007. 3(1): 1527.

22. Al-Bayaty FH, Abdulla MA, Hassan MIA, Roslan SNB, Hussain SF, Said HBB. Effect of mouthwash extracted from Miswak (Salvadora Persica) on periodontal pathogenic bacteria an in-vitro study. in Science and Social Research (CSSR), 2010 International Conference on. 2010. IEEE. 